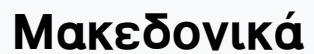

Tóp. 4, Ap. 1 (1960)

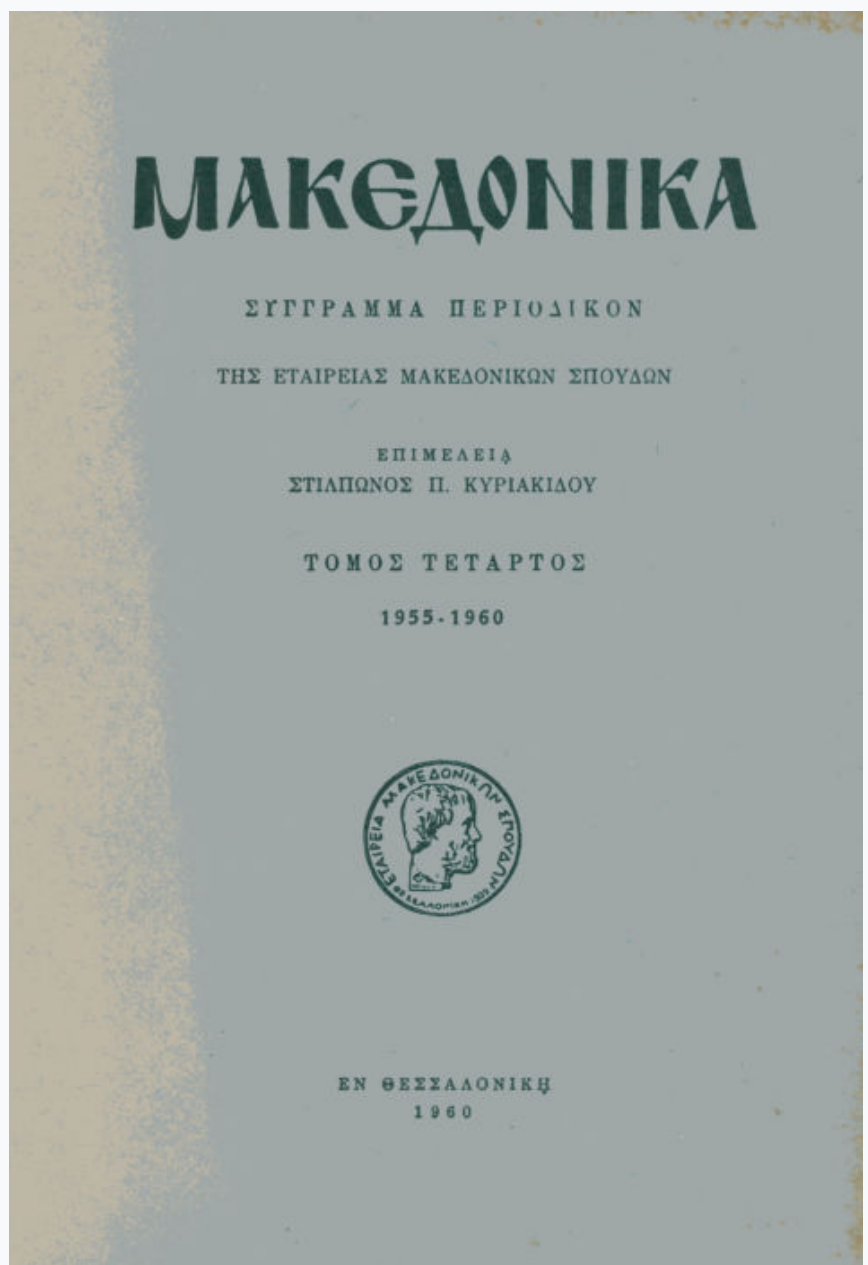

\section{Christophoros Naltsas, Der San Stephano Vertrag und das Griechentum}

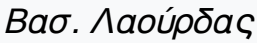

doi: 10.12681/makedonika.710

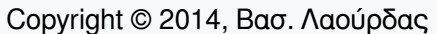

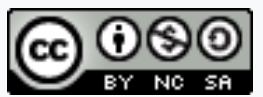

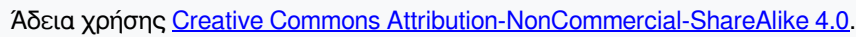

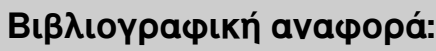

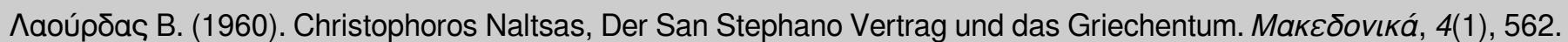
https://doi.org/10.12681/makedonika.710 


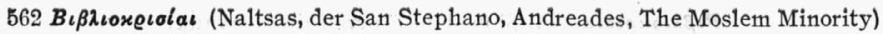

Christophoros Nalts a s, Der San Stephano Vertrag

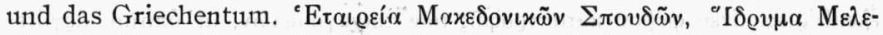

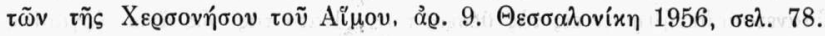

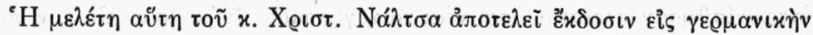

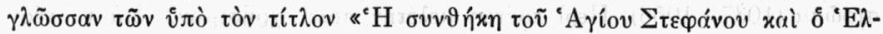

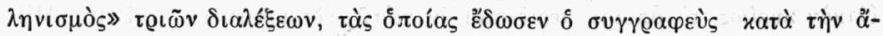

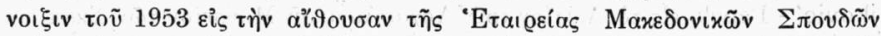

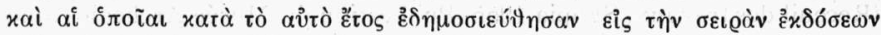

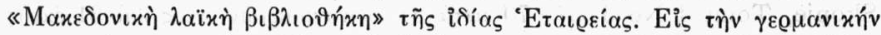

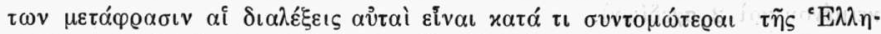

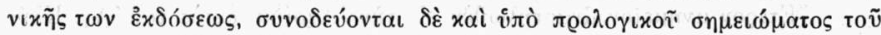

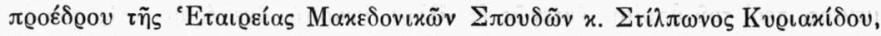

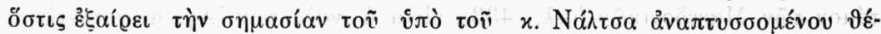

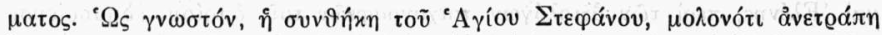

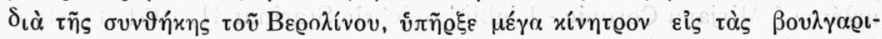

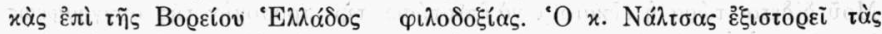

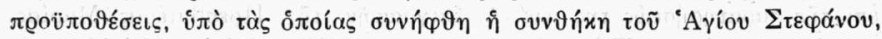

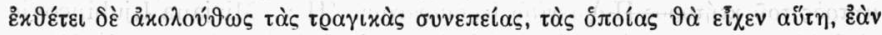

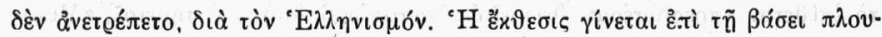

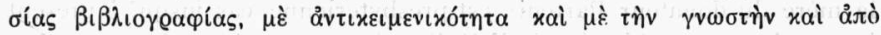

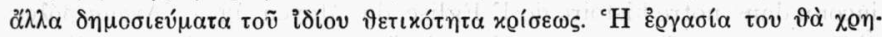

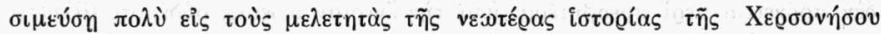

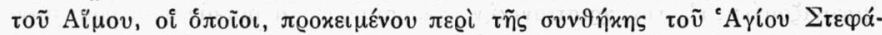

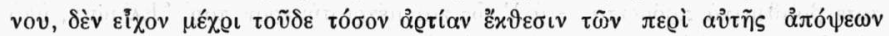
$\tau \tilde{\eta} \varsigma{ }^{\circ} E \lambda \lambda a ́ \delta o s$.

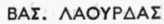

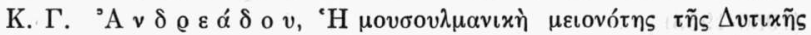

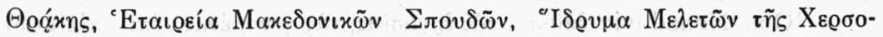

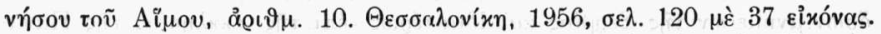

K. G. Andreades, The Moslem Minority in Western

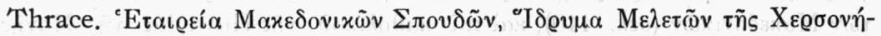

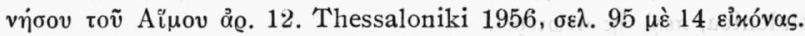

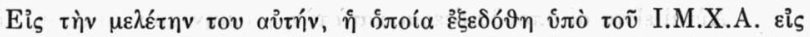

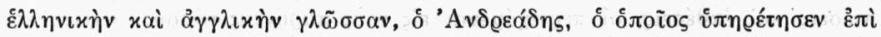

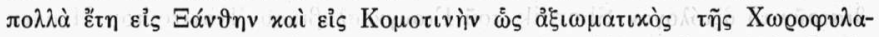

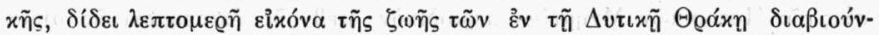

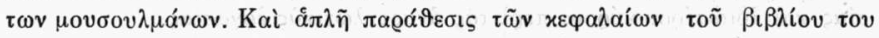

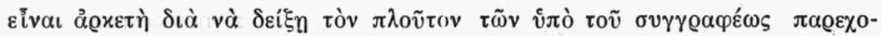

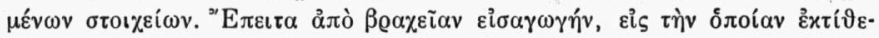

